\title{
Effervescent Granules for Oral Suspension
}

National Cancer Institute

\section{Source}

National Cancer Institute. Effervescent Granules for Oral Suspension. NCI Thesaurus.

Code C149473.

Solid preparation consisting of effervescent granules intended to be dispersed or dissolved in the specified liquid, which is supplied in the same packaging, to obtain an oral suspension. 